\title{
Pattern of Drugs Use in Selected Paediatric Diseases in Outpatients Departments of Public and Private Teaching Hospitals in Bangladesh
}

\author{
Tasnin Afrin, ${ }^{1}$ Rumana Afroz, ${ }^{2}$ Shahin Sultana, ${ }^{3}$ Kamrunnes $a,{ }^{4}$ Mahbuba Jahan Lotus ${ }^{5}$
}

\begin{abstract}
Background \& objective: Appropriate use of drugs are important in any diseases in any population. It is particularly so in children. To evaluate whether drugs are properly utilized in terms of efficacy, safety, convenience and economic aspects at all levels in the chain of drug use, periodic studies addressing the utilization of drugs in different health care setting are essential. Various drug utilization studies have been carried out all over the world but there are limited studies addressing drug use patterns in pediatric population in Bangladesh. The present study is one such step to evaluate the pattern of drug use in different pediatric diseases among patients attending at pediatric out-patient department (OPD) in two selected medical college hospitals.
\end{abstract}

Methods: This cross-sectional study was conducted in the paediatric OPD of two tertiary care hospitals, Sir Salimullah Medical College \& Mitford Hospital (SSMC \& MH) (a public hospital), Dhaka and Dhaka National Medical College (DNMC) \& Hospital (a private hospital). A total of 600 children (300 from each of the two Medical College Hospitals) were selected as study subjects. Three hundred prescriptions audited in SSMC \& MH contained a total 946 drugs and 300 prescriptions audited in DNMC contained 990 drugs in total. Patients got admitted during out-patient department visit were excluded from the study. The age and sex of the patients and medications use-related variables like dose, frequency, duration and route of administration of the drugs were noted. Pattern of drug use in the hospitals for pediatric population was evaluated.

Results: The study subjects of the two tertiary hospitals were almost identical in terms of age and sex ( $p=$ 0.181 and $p=0.369$ respectively). Use of three drugs per encounter was commonly observed in both the hospitals. Around one-third of the prescriptions contained four drugs. Prescription of five drugs was rare in both the hospitals. Prescription with two drugs was higher in SSMC \& MH than that in DNMC Hospital $(p=0.043)$. Majority of the prescriptions from SSMC (83.1\%) contained drugs within essential drug list (EDL) compared to that from DNMC $(73 \%)(p<0.001)$. The highest prescribing drug was antibiotic, both in SSMC $(22.7 \%)$ and DNMC $(23.2 \%)(p=0.417)$ followed by analgesic (18\% in SSMC and $17.7 \%$ in DNMC), anti-diarrhoeal. The less commonly used drugs were gastric acid suppressant, antispasmodic, anthelmintic, antiemetic, while rarely prescribed drugs were antihistamines, antiasthmatic and nasal drops. Pattern of drugs prescribed in two hospitals were similar $(p>0.05)$.

Conclusion: The study concluded that the rate of antibiotics prescribed in both public and private hospitals is higher. Further studies teaching hospitals etc. are required for the monitoring of drug utilization pattern and formulation of Standard Treatment Guidelines (STG) for the physicians is essential.

Key words: Pattern of drug use, Pediatric diseases, Outpatients department, Public \& private teaching hospitals etc.

\section{Authors' information:}

'Dr. Tasnin Afrin, Assistant Professor, Department of Pharmacology \& Therapeutics, Dhaka Community Medical College. Dhaka.

${ }_{2}^{2}$ Dr. Rumana Afroz, Assistant Professor, Department of Pharmacology \& Therapeutics, Dhaka Medical College. Dhaka.

${ }^{3}$ Dr. Shahin Sultana, Assistant Professor, Department of Pharmacology \& Therapeutics, Mymensingh Medical College, Mymensingh.

${ }_{4}^{4}$ Dr. Kamrunnesa, Assistant Professor, Department of Pharmacology \& Therapeutics, Shahabuddin Medical College, Dhaka.

${ }_{5}^{5}$ Dr. Mahbuba Jahan Lotus, Assistant Professor, Department of Pharmacology \& Therapeutics, Dhaka Medical College, Dhaka.

${ }^{6}$ Prof Dr. Ferdous Ara, Department of Pharmacology, Delta Medical College, Dhaka

Correspondence: Dr. Tasnin Afrin, Cell Phone: +8801726138327, E-mail: ujala1410@gmail.com 


\section{INTRODUCTION:}

Pediatrics is the branch of medicine dealing with the development, diseases and disorders of children. ${ }^{1}$ Drug therapy is considered to be the major component of pediatric management in health care settings like hospital. The use of antimicrobial agents, specially antibiotics has become a routine practice for the treatment of pediatric illness. ${ }^{2}$ However, there are also reports of an irrational use of antibiotics, ${ }^{3}$ which may even lead to infections worse than originally diagnosed ones. Inappropriate prescribing is a recognized worldwide problem of the healthcare delivery system. ${ }^{4}$ The rational prescribing can be assessed with the help of conducting prescription audit on continuous basis. In recent years, drug utilization studies are found to be useful tool to facilitate rational use of drugs in health care delivery systems. It truly reflects the status of health care system. Various indicators have been developed by International Network for the Rational Use of Drugs (INRUD) to allow for assessment of drug use practices and suggesting remedial measures. ${ }^{5}$ Many studies point to major misconceptions \& misuse of medicines. The design of drug use indicator studies, however varies from settings to settings. While a large number of drug utilization studies are available for adults all over the world, ${ }^{6,7}$ a few studies provide information on drug use patterns in pediatrics.

Pediatrics is among the most vulnerable population group in terms of disease acquisition. Besides, pharmacodynamic and pharmacokinetics are different in children, which often make them more susceptible to various adverse drug reactions. 8,7 Additionally, the impact of maternal drug intake on neonates is also relevant in this context. Such issues therefore call for close monitoring of drug prescribing trends in neonates and infants.9,10 Besides, due to economic and ethical issues, children do not often participate in clinical trials and specific knowledge about effect of drugs in children is often inadequate. ${ }^{11}$ Another common problem encountered in children is failure to comply with therapeutic regimen due to either inconvenient dosing schedule and/or large number of medicines prescribed. ${ }^{12}$ Study of drug utilization pattern in a particular setting gives an idea about the prescribing practices and characterizes the early signals of irrational drug use. With the help of WHO prescribed drug use indicators and concept of defined daily doses it is possible to compare drug utilization patterns between different settings. ${ }^{13}$ Appropriate drug utilization studies are, therefore, important tools to evaluate whether drugs are properly utilized in terms of efficacy, safety, convenience and economic aspects at all levels in the chain of drug use. ${ }^{14}$ Various drug utilization studies have been carried out all over the world but there are limited studies addressing drug use patterns in pediatric population in Bangladesh.

Therefore, the present study was undertaken to evaluate the pattern of drug use in different pediatric diseases. Out-patient Department of two tertiary level hospitals in Bangladesh, which may help clinicians to take appropriate measure for the improvement of prescribing pattern and use of essential drugs to prevent prescribing errors and thus promote rational use of drugs.

\section{METHODS:}

This cross-sectional descriptive study was carried out in the pediatric out-patient department (OPD) of two tertiary care hospitals. The study population included children attending at Paediatrics OPD in Sir Salimullah Medical College \& Mitford Hospital, Dhaka and Dhaka National Medical College \& Hospital. A total of 600 children (300 from each of the two selected Medical College Hospitals) were selected as study subjects. However, patients got admitted during out-patient department visit were excluded from the study. The study population were classified as low income group (monthly income $<10000$ / month), middle income group (monthly income 10000-20000/ month) and high-income group (monthly income $>20000 /$ month). The demographic characteristics like age and sex of the patients and medications use-related variables like dose, frequency, duration and route of administration of drugs were recorded. Pattern of drug used in the selected hospitals for pediatric population was evaluated with the help of World Health Organization's Core Drug Indicators to Investigate Drug Use in Health Facilities as follows (Table I): 


Table I. World Health Organization Core Drug Indicators to
Investigate Drug Use in Health Facilities
WHO core drug use indicators
Prescribing indicators
1. Average number of drugs per prescription
2. Percentage of drugs prescribed by generic name
3. Percentage of encounters with an antibiotic prescribed
4. Percentage of encounters with an injection prescribed
5. Percentage of drugs prescribed from Essential Drug List or formulary
Patient care indicators*
6. Average consultation time
7. Average dispensing time
8. Percentage of drugs actually dispensed
9. Percentage of drugs adequately labeled
10. Patient's knowledge of correct dosage
Facility indicators
11. Availability of copy of Essential Drug List or formulary
12. Availability of key drugs
Some additional indices
13. Percentage of encounters with other drugs

\section{*Number 6-10 were not included in current study}

The total number of drugs prescribed for 300 patients of SSMC \& MH was 946 and that prescribed for 300 patients of DNMC was 990. The most commonly prescribed drugs were noted. The number of drugs prescribed from essential drug list of Bangladesh was also studied. Data were analyzed using SPSS and the test statistics used to analyze the data were descriptive statistics and Chi-squared $\left(\chi^{2}\right)$. Level of significance was set at $5 \%$ and $p$-value $<0.05$ was considered significant.

\section{RESULT:}

The pediatric patients included from the two tertiary hospitals were almost similar in terms of age distribution with 1-6 years age group was the predominant $(p=0.181)$ (Table II). The sex distribution was also identical between the study groups ( $p=0.369$ ) (Fig. 1). Use of three drugs per encounter was commonly observed in both the hospitals. Around one-third of the prescriptions contained four drugs. Prescription of five drugs was rare in both the hospitals. Prescription with two drugs was higher in SSMC than that in DNMC $(p=0.043)$ (Table III). Majority of the prescriptions from SSMC
(83.1\%) contained drugs within EDL compared to that from DNMC $(73 \%)(p<0.001)$ (Table IV). The highest prescribing drug was antibiotic, both in SSMC $(22.7 \%)$ and DNMC $(23.2 \%)(p=0.417)$ followed by analgesic (18\% in SSMC and $17.7 \%$ in DNMC) and anti-diarrhoeal (10.5\% in SSMC and $10.1 \%$ in DNMC). The less commonly used drugs were gastric acid suppressant, antispasmodic, anthelmintic, antiemetic, while rarely prescribed drugs were antihistamines, antiasthmatic and nasal drops. Pattern of drugs prescribed in two hospitals were almost similar ( $p>$ 0.05) (Table V).

\begin{tabular}{|c|c|c|c|}
\hline \multirow[b]{2}{*}{ Age(years) } & \multicolumn{2}{|c|}{ Study Area } & \multirow[b]{2}{*}{${ }^{*}$-value } \\
\hline & $\begin{array}{c}\text { SSMC } \\
(n=300)\end{array}$ & $\begin{array}{c}\text { DNMC } \\
(n=300)\end{array}$ & \\
\hline $0-1$ & $84(28.0)$ & $63(21.0)$ & \multirow{4}{*}{0.181} \\
\hline $1-6$ & $124(41.3)$ & $128(42.7)$ & \\
\hline $6-10$ & $82(27.3)$ & $94(31.3)$ & \\
\hline $10-12$ & $10(3.3)$ & $15(5.0)$ & \\
\hline
\end{tabular}

*Data were analyzed using Chi-squared $\left(\chi^{2}\right)$ Test and were presented as n(\%). Figures in the parentheses denote corresponding percentage.

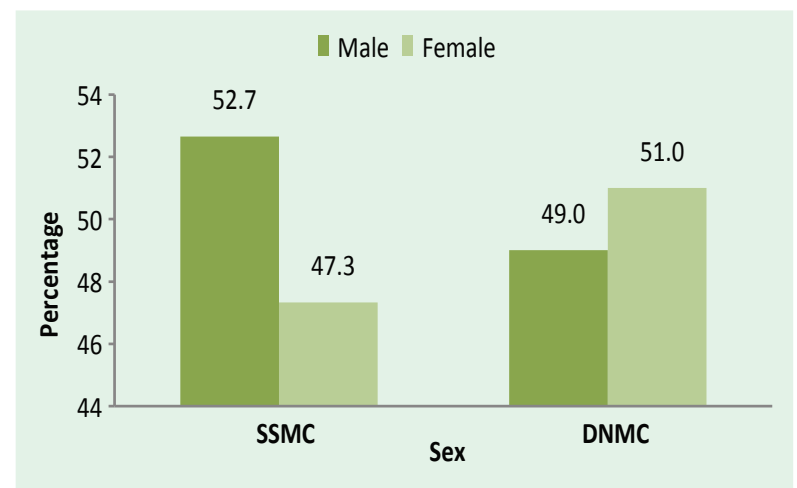

Figure 1: Distribution of sex by patients admitted in hospital

\begin{tabular}{llcl} 
Table III.Number of drugs prescribed per prescriptions & \\
\cline { 1 - 2 } $\begin{array}{l}\text { Prescriptions } \\
\text { containing number } \\
\text { of drugs }\end{array}$ & $\begin{array}{c}\text { SSMC } \\
(\mathrm{n}=300)\end{array}$ & $\begin{array}{c}\text { DNMC } \\
(\mathrm{n}=300)\end{array}$ & *p-value \\
\hline Two & $60(20.1)$ & $40(13.3)$ & \\
Three & $140(46.6)$ & $145(48.4)$ & 0.043 \\
Four & $94(31.3)$ & $100(33.3)$ & \\
Five & $6(2.0)$ & $15(5.0)$ &
\end{tabular}

${ }^{*}$ Data were analyzed using Chi-squared $\left(\chi^{2}\right)$ Test and were presented as n(\%). Figures in the parentheses denote corresponding percentage. 


\begin{tabular}{|c|c|c|c|}
\hline \multirow[b]{2}{*}{ EDL drugs } & \multicolumn{2}{|c|}{ Study Area } & \multirow[b]{2}{*}{${ }^{*} p$-value } \\
\hline & $\begin{array}{c}\text { SSMC } \\
(n=300)\end{array}$ & $\begin{array}{c}\text { DNMC } \\
(n=300)\end{array}$ & \\
\hline Drugs included within EDL & $786(83.1)$ & $723(73.0)$ & \multirow{2}{*}{$<0.001$} \\
\hline Drugs excluded from EDL & $160(16.9)$ & $267(27.0)$ & \\
\hline
\end{tabular}

*Data were analyzed using Chi-squared $\left(\chi^{2}\right)$ Test and were presented as $\mathbf{n}(\%)$.

Figures in the parentheses denote corresponding percentage.

\begin{tabular}{|c|c|c|c|}
\hline \multirow{2}{*}{$\begin{array}{l}\text { Most common } \\
\text { pharmacological } \\
\text { group }\end{array}$} & \multicolumn{2}{|c|}{ Study Area } & \multirow{2}{*}{${ }^{*} p$-value } \\
\hline & $\begin{array}{c}\text { SSMC } \\
(n=300)\end{array}$ & $\begin{array}{c}\text { DNMC } \\
(n=300)\end{array}$ & \\
\hline Analgesic and antipyretic & $170(18.0)$ & $175(17.7)$ & 0.866 \\
\hline Antibiotic & $215(22.7)$ & $230(23.2)$ & 0.792 \\
\hline Expectorants \& bronchodilators & $78(8.2)$ & $88(8.9)$ & 0.613 \\
\hline Antihistamines & $33(3.5)$ & $35(3.5)$ & 0.955 \\
\hline Antiasthmatics & $22(2.3)$ & $26(2.6)$ & 0.671 \\
\hline Nasal drops & $32(3.4)$ & $36(3.6)$ & 0.762 \\
\hline Anti-diarrheal & $100(10.5)$ & $100(10.1)$ & 0.734 \\
\hline Antiemetic & $63(7.4)$ & $55(5.5)$ & 0.310 \\
\hline Gastric acid suppressants & $80(8.4)$ & $86(8.7)$ & 0.856 \\
\hline Antispasmodic & $83(8.7)$ & $84(8.5)$ & 0.821 \\
\hline Anthelmintic & $70(7.4)$ & $75(7.5)$ & 0.883 \\
\hline
\end{tabular}

*Data were analyzed using Chi-squared $\left(\chi^{2}\right)$ Test and were presented as $\mathbf{n}(\%)$.

Figures in the parentheses denote corresponding percentage.

\section{DISCUSSION:}

The present study was intended to assess the prescribing pattern of drugs for paediatric patients at the tertiary level hospitals. The tertiary level hospitals have been chosen because the prescribing patterns of the out patients department of tertiary level hospitals are often copied by community practitioners and health workers. Irrational use of drugs is common in developing countries with a high rate of polypharmacy, overuse of antibiotics, use of off-level drugs and drugs with improper efficacy. Several studies have documented prescribing practice in different countries. But there is still dearth of information on the prescribing pattern of drugs in paediatrics. In the present study it was observed that the average number of drugs per prescription was significantly higher than recommended by WHO/ INRUD. Trade names were used more often and generic prescribing was remarkably lower at private sector.

Essential medicines and rational use of medicines are two sides of a coin - inseparable from each other and mutually dependent. Increase in the use of essential medicines makes the medication therapy more rational. ${ }^{15}$ In this study, $83 \%$ of the medicines could be considered as essential in Sir Salimullah Medical College \& Hospital and $73 \%$ could be rated as essential in Dhaka National Medical College \& Hospital. A study conducted in three tertiary hospitals of Delhi reported 96, 94 and $74 \%$ of essential medicines prescribed ${ }^{16}$ indicating that prescribing behavior in India for pediatric age-group is better than that in our country. One reason for this could be an effective and successful implementation of NEML (National Essential Medicine List) in government hospitals of Delhi. There is a pressing need for studies into how medicines are being prescribed to children in various settings and populations. Studies that have investigated prescribing in populations have found high prescribing rates although a limited formulary of medications is used. ${ }^{17}$ More medicines increase the risk of drug interactions, adversely affecting the patient compliance and hike the cost of treatment. ${ }^{18}$

Indiscriminate or prolonged prophylactic use of new antibiotics has been shown to contribute to the emergence of multi-resistant strains in the hospital settings. Like antibiotics, it is difficult to justify the use of analgesics on such a large scale, taking into account that prolonged and excessive use of analgesics may cause potential hazards. ${ }^{19}$ In Bangladesh doctors more often prescribe drugs irrationally to give quick relief of the patients without taking into consideration of the patient's disease condition and age. ${ }^{16}$ Data obtained from the study, however, do not support the claims that the private sector hospitals are more efficient and accountable in rational prescribing of medications than the public sectors do. ${ }^{20,21}$

Inappropriate drug prescribing is a global problem. ${ }^{22}$ Misuse of drugs occurs in all countries. The irrational prescribing behavior is especially common and costly 
in developing countries. Such practices include polypharmacy, use of wrong or ineffective drugs, underuse and incorrect use of effective drugs, use of combination products which are often more costly and offer no advantage over single compounds and overuse of antimicrobials and injections. ${ }^{23}$ Affordable medicine prices are an important prerequisite for ensuring access to essential drugs in the public and private sectors. High drug prices lead to barrier towards affordability. ${ }^{24}$ It is one of the specific objectives of the National Medicine Policy, which emphasize on access to equitable availability and affordability of essential medicines to those who need them. ${ }^{25}$ When the drug-price is high, the consumers often purchase them, in small quantities, rather than in therapeutic amounts. The widespread prescription and sale of non-essential drugs means that households, especially poor households, are not getting the best health care for their money. ${ }^{26}$

Despite resource constraint in health sector, particularly in drug supply, specific improvements in management of drugs, could reduce wastage and irrational use, which in turn, will make availability of essential drugs without increasing their expenses. ${ }^{27}$ Prescribing pattern need to be evaluated periodically to increase the therapeutic efficacy, decrease adverse effects and provide feedback to the prescribers. ${ }^{28}$ Drug utilization appraisals are useful for obtaining information about drug use pattern and their costs. ${ }^{29}$ The causes of access gap to essential drugs and the measures which are needed to close the gap is linked to a set of fundamental economic, social and educational factors that lie beyond the health sector system. ${ }^{30}$ However, it should be borne in mind that access to essential medicines helps to reduce disease burden. ${ }^{24}$

\section{CONCLUSION:}

The study concluded that the incidence of antibiotics prescribed in both public and private hospitals seems to be higher. Periodic studies for monitoring of drug utilization pattern in different health care settings and formulation of Standard Prescribing Guidelines (STG) for the physicians is essential, which will help assuring rational use of drugs, thereby reducing the unnecessary drug interactions \& health expenditure.

\section{REFERENCES}

1. Ghai OP, Paul VK, Rational drug therapy in pediatric practice. Indian Pediatr 1988;25:1095-1109.

2. Summers RS, Summers B, Drug prescribing in pediatrics. Ann Trap Paediatr 1986;6:129-33.

3. Principi N. Control of antibiotic therapy in pediatric patients. Developmental Pharmacology and Therapeutics 1981;2: 145-55.

4. WHO, Report of a conference of experts, Nairobi, November. (1985). The rational use of drugs. Geneva, 1987:24-29.

5. Laporte JR, Porta M, Capella D. Drug utilization studies: a tool for determining the effusiveness of drug use. Brnk J Clin Pharmacol 1983;16:301-304.

6. Guyon AB, Barman A, Ahmed AU, Alam MS. A baseline survay on use of drugs at the primancy health care level in Bangladesh. Bull WHO 1994;72:265-271.

7. Vallano A, Montene E, Arnau JM, Vidal X. Medical specialty and pattern of medicines prescription. Eur J clin Pharmacol 2004;60:725-730.

8. Ginsberg G, Hattis D, Sonawane B, Russ A. Evaluation of Child/Adult Pharmacokinetic Defferences from a database derived from the therapeutic Drug Literature. Toxicol Sci 2002;66:185-200.

9. Takahashi H, Ishikawa S, Nomoto S. Development changes in Pharmacokinetics and Pharmacodynamics of warferin enantiomars in Japanese Children. Clin Pharmacol Ther 2000;68:541-555.

10. Hanne M, Morten A, Josper H. Drug Prescribing in Danish Children: a population based study, Pharmacoepidemiology and prescription. Eur J Clin Pharmacol 2001;57:159-165.

11. Karande S, Sankhe P, Kulkarne M. Patterns of prescription and drug dispensing. Ind J Pediatr 2005;72:117-121.

12. Strand, J, Rokstad, K, Heggedal, U. Drug prescribing for children in general practice: $\mathrm{A}$ report from the More and Romsdal Prescription study. Acta Paediatrica 1988;89: 218-224.

13. World Health Organization (WHO). Rational use of medicines; India 2003. Available from: http:// www. whoindia.com

14. Clavenna A, Sequi M, Bortolotti A, Morlino L, Fortino I, Bonati M. Determinants of drug utilization profile in the pediatric population in Italy. British Journal of Clinical Pharmacology 2009;67(5):565-71.

15. Desai S. Essential drugs and rational drug therapy. Bull soc Rational Ther 2001;12:2-7.

16. Biswas NR, Biswas RS, Pal PS. Patterns of prescriptions and drug use in two tertiary hospitals in Delhi. Indian J Physiol Pharmacal 2000;44:109-12. 
17. Strand J, Rokstad K, Heggedal U. Drug prescribing for children in general practice: A report from the More and Romsdal Prescription study. Acta Paediatrica 1988;89: 218-224.

18. Mirza NY, Desai S, Ganguly B. Prescribing pattern in a pediatric outpatient department in Gujarat. Bangladesh $J$ Pharmacal 2009;4:39-42.

19. Smith $\mathrm{AJ}$, Aronson $\mathrm{KJ}$, Thomas M. Antibiotic policies in the developing world. Eur J of Clin Pharmacal 1991;41:85-87.

20. Rosenthal G, Newbrander W. Public policy and private sector provision of health services. Int J Health Plann Manage 1996;11:203-216.

21. Bustreo F, Harding A, Axelson H. Can developing countries achieve adequate improvements in child health outcomes without engaging the private sector. Ball World Health Organization 2003;81:886-895.

22. Enwere OO, Falade CO, Salako BL. Drug prescribing pattern at the medical outpatient clinic of a tertiary hospital in southwestern Nigeria. Pharmacoepidemiol Drug Saf 2007; 16:1244-9.

23. Blum NL. Drug Information Development. A Case Study Nepal. Rational Pharmaceutical Management Project. United States Pharmacopoeia. (Online) 2000. Available from URL: http://www.usp.org/pdf/EN/dqi/nepal Case Study.pdf.
24. Tettch EK. Provide affordable essential medicines to African households: The missing policies and institution for price containment. Soc Sci and med 2008;66:569-581.

25. Ahmed H, Ibrahim M, Babar Z. Affordability of essential medicines used for treating chronic diseases in Malaysia: An academic perspective. The Internet Journal of Third World Medicine 2009;8:1.

26. World Health Organization (WHO). How to develop and implement a rational drug policy $2^{\text {nd }}$ ed. Geneva: WHO, 2001.

27. Boston, MA. Managing drug supply: the selection, procurement, distribution and the use of pharmaceuticals in primary health care 1981:18-19.

28. Kumari R, Idris MZ, Bhushan V, Khanna A, Agarwal M, Singh SK. Assessment of prescribing pattern at the public health facilities ofLucknow district. Indian J Pharmacol 2008; 40:243-247

29. Marshner JP, Thurmann P, Harden S, Rietbrock N. Drug utilization review on a surgical intensive care unit. Int J Clin Pharmacol Ther 1994;32:447-451.

30. Quick JD. Essential medicines twenty five years on: closing the access gap. Health policy and planning 2003;18:1-3. 